Economics Development Analysis Journal 5(2)(2016)

\title{
Hambatan dan Strategi Pengembangan Usahatani Kopi dalam Upaya Peningkatan Produksi
}

\section{Retno Rahmawati Pratiwi ${ }^{1 凶}$}

${ }^{1}$ Jurusan Ekonomi Pembangunan, Fakultas Ekonomi, Universitas Negeri Semarang

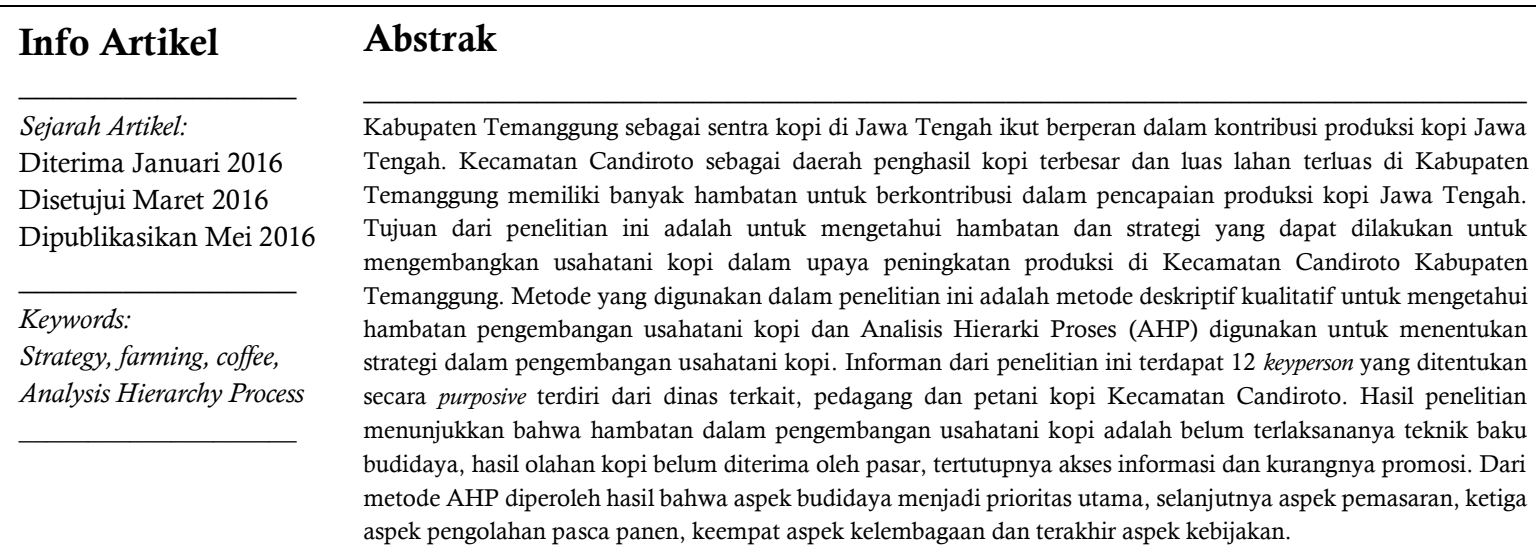

\begin{abstract}
Temanggung District as the center of Central Java coffee get in important contribution for Central Java in a part of producing coffee. Candiroto Subdistrict as the largest coffee producing region with the largest land area in Temanggung District, has many obstacles contribution on Central Java by targeting producing of coffee. The purpose of this study was to know the obstacles and development strategy that can do for increasing the producing of coffee in Candiroto Subdistrict Temanggung. The method used in this researh is descriptive qualitative method for known as obstacles in the development coffee farming and the Analysis Hierarchy Process (AHP) used for determine development strategy on coffee farming. Informants in the research are 12 key persons. They determined for purposively between government, trader, and coffee farmer in the Candiroto Subdistrict. The results showed that the obstacles in the development of coffee farming is not yet implement the techniques of cultivation, raw processed of coffee has not been accepted by the closed market access in order to inform and it also still lack of promotion. From the method of AHP results obtained that the cultivation aspect becomes a top priority, the next aspect of marketing, post-harvest processing of the three aspect, and the institutional aspects of thr fourth and the last aspect of thr policy.
\end{abstract}

(C) 2016 Universitas Negeri Semarang

\footnotetext{
Alamat korespondensi:

Ruang Jurnal Gedung L FE UNNES, Sekaran Gunungpati

Semarang, 50229, Indonesia

E-mail: retnorahmawati36@gmail.com
} 


\section{PENDAHULUAN}

Kopi merupakan salah satu komoditas unggulan dalam sektor perkebunan Indonesia. Peran komoditas kopi bagi perekonomian Indonesia cukup penting, baik sebagai sumber pendapatan bagi petani kopi, sumber devisa, penghasil bahan baku industri, maupun penyedia lapangan kerja melalui kegiatan pengolahan, pemasaran, dan perdagangan (ekspor dan impor) (Ditjen Perkebunan, 2015). Mata pencarian 100 juta orang bergantung kepada kopi (Pendergrast, 1999 dalam Bunn et al., 2015). Indonesia menjadi negara penghasil kopi terbesar keempat di dunia dari semua negara eksportir kopi setelah Brasil, Vietnam dan Colombia (ICO, 2015). Komoditas kopi Indonesia sudah masuk ke pasar ekspor dengan negara tujuan ekspor terbesar diantaranya adalah Malaysia, Amerika Serikat, Jerman, dan Jepang. Amerika Serikat menjadi negara tujuan utama dan terbesar ekspor kopi Indonesia dengan total nilai pada tahun 2014 sebesar US\$295.988.228.

Selain menjadi eksportir kopi terbesar, berdasarkan data International Coffee Organization konsumsi kopi Amerika Serikat meningkat yang sebelumnya 23.417.000 kantung, tahun 2014 menjadi 23.761 .000 kantung $(2,5 \%)$. Sedangkan untuk konsumsi kopi Indonesia selama tahun 2010-2014 mengalami peningkatan dengan ratarata pertumbuhan sebesar $7,7 \%$. Berdasarkan data International Coffee Organization konsumsi kopi dunia mengalami peningkatan selama tahun 2010-2014 dengan konsumsi kopi tertinggi adalah Eropa, Asia Tenggara kemudian Amerika dan ditargetkan akan terus mengalami peningkatan. Popularitas dan daya tarik di seluruh dunia kopi, yang berasal dari rasa yang unik, membuatnya saat ini salah satu minuman yang paling diinginkan dan sering dikonsumsi (Ayelign \& Sabally, 2013). Kenaikan konsumsi kopi yang terjadi di dunia menjadi peluang bagi Indonesia sebagai negara produsen sekaligus eksportir kopi untuk terus meningkatkan produksi dan kualitas kopi dalam negeri untuk memenuhi permintaan baik dalam negeri maupun luar negeri.

Daerah penghasil kopi terbesar di Indonesia adalah Sumatera, Jawa dan Sulawesi. Provinsi dengan kontribusi produksi kopi terbesar di Pulau Jawa adalah Jawa Timur dan Jawa Tengah. Provinsi Jawa Tengah menjadi produsen kopi terbesar kedua setelah Jawa Timur. Bagi Provinsi Jawa Tengah kopi merupakan salah satu komoditas perkebunan yang cukup berpotensi terutama jika dilihat dari proporsi luas lahan tanaman kopi seluas 39.750 ha $(5,09 \%)$, dari total luas komoditas perkebunan di Jawa Tengah 781.518,38 ha. Produksi kopi Jawa Tengah tahun 2014 sebesar 20.290 ton, produksi tersebut mengalami penurunan dibanding tahun 2013 sebesar 20.310 ton, dengan luas lahan yang sama. Pedagang kopi hanya menjual kopi di pasar lelang pusat (Petit, 2007 dalam Gelaw et al., 2016). Berbeda dengan Jawa Timur yang mengalami kenaikan produksi pada tahun 2014 dibanding tahun 2013 dengan total luas lahan yang sama. Hal tersebut dapat terjadi karena pola pengelolaan perkebunan kopi di Jawa Tengah sebagian besar dilakukan secara tradisional, akan tetapi potensinya masih bisa ditingkatkan melalui pengelolaan intensif. Berdasarkan RENSTRA Direktorat Jenderal Perkebunan Tahun 2015-2019 proyeksi perkebunan untuk komoditas kopi tahun 2015 sebesar 724.780 ton, dan Provinsi Jawa Tengah diproyeksikan produksi kopi tahun 2015 sebesar 22.570 ton

Sentra kopi di Provinsi Jawa Tengah adalah Kabupaten Temanggung yang memiliki luas tanaman kopi sebesar 9.536,37 ha (23,99\%), dari total luas tanaman kopi Jawa Tengah. Selain itu, Kabupaten Temanggung memberikan kontribusi untuk total produksi kopi Jawa Tengah dengan menyumbang $11.560,27$ ton $(56,97 \%)$, dari total produksi kopi Jawa Tengah. Kabupaten Temanggung memiliki 2 jenis kopi yang diusahakan terlihat pada Tabel 1 berikut ini: 
Tabel 1. Luas Lahan dan Produksi Kopi Kabupaten Temanggung Tahun 2010-2014

\begin{tabular}{lcccc}
\hline \multirow{2}{*}{ Tahun } & \multicolumn{2}{c}{ Kopi Arabika } & \multicolumn{2}{c}{ Kopi Robusta } \\
& $\begin{array}{c}\text { Luas Lahan } \\
(\mathrm{Ha})\end{array}$ & $\begin{array}{c}\text { Produksi } \\
(\text { Ton })\end{array}$ & $\begin{array}{c}\text { Luas Lahan } \\
(\mathrm{Ha})\end{array}$ & $\begin{array}{c}\text { Produksi } \\
(\text { Ton) }\end{array}$ \\
\hline 2010 & $4.594,62$ & $1.485,20$ & $8.919,73$ & $4.807,89$ \\
2011 & $5.185,32$ & 820,00 & $9.263,02$ & $2.514,22$ \\
2012 & $5.864,14$ & $2.010,99$ & $9.256,28$ & $8.518,95$ \\
2013 & $6.561,07$ & $2.157,63$ & $8.158,55$ & $7.388,79$ \\
2014 & $7.088,30$ & $2.422,74$ & $8.158,55$ & $10.254,32$
\end{tabular}

Sumber : BPS 2015, Temanggung Dalam Angka (diolah)

Berdasarkan Tabel 1 luas lahan kopi arabika selama tahun 2010-2014 mengalami kenaikan, untuk kopi robusta luas lahan dan produksi selama tahun 2010-2014 mengalami fluktuasi. Pada tahun 2011 menjadi awal kenaikan luas lahan untuk kopi arabika dan robusta. Akan tetapi kenaikan luas lahan tidak diimbangi dengan kenaikan produksi, produksi kopi arabika dan robusta turun dari tahun 2010 menjadi 820,00 ton $(-81,12 \%)$ dan $2.514,22$ ton (91,23\%). Penurunan produksi dapat terjadi karena adanya pembaharuan pohon kopi, penggunaan pupuk yang berlebihan pada tahun sebelumnya, kemarau panjang, atau kesalahan pada pemotongan cabang kopi, sedangkan penurunan luas lahan dapat terjadi karena adanya alih fungsi lahan.

Kopi sebagai komoditas unggulan Kabupaten Temanggung tidak dapat dipisahkan dari peran antar wilayah yang ikut berkontribusi dalam menyumbang perekonomian Kabupaten Temanggung, seperti terlihat dalam Tabel 2 berikut :

Tabel 2. Luas Area, Produksi, Produktivitas dan Jumlah Petani Kopi Kabupaten Temanggung Tahun 2014

\begin{tabular}{llcccc}
\hline No & Kecamatan & $\begin{array}{c}\text { Luas Area } \\
(\mathrm{Ha})\end{array}$ & $\begin{array}{c}\text { Produksi } \\
(\text { Ton })\end{array}$ & $\begin{array}{c}\text { Produktivitas } \\
(\mathrm{kg} / \mathrm{ha})\end{array}$ & $\begin{array}{c}\text { Jumlah } \\
\text { Petani }\end{array}$ \\
\hline 1. & Parakan & 2,90 & 2,95 & $1.017,40$ & 12 \\
2. & Bulu & 16,15 & 16,90 & $1.046,30$ & 156 \\
3. & Temanggung & 26,24 & 26,04 & 992,30 & 305 \\
4. & Tembarak & 14,40 & 14,10 & 979,50 & 232 \\
5. & Kranggan & 41,16 & 47,15 & $1.145,50$ & 572 \\
6. & Pringsurat & $1.010,00$ & $1.267,85$ & $1.255,30$ & 5.527 \\
7. & Kaloran & 398,42 & 488,22 & $1.225,40$ & 1.453 \\
8. & Kandangan & $1.124,46$ & $1.426,38$ & $1.268,50$ & 5.762 \\
9. & Kedu & 126,30 & 143,64 & $1.137,30$ & 418 \\
10. & Ngadirejo & 13,37 & 14,78 & $1.105,46$ & 205 \\
11. & Jumo & 601,22 & 760,96 & $1.265,70$ & 2.324 \\
12. & Candiroto & $\mathbf{1 . 6 1 9 , 8 0}$ & $\mathbf{2 . 0 4 0 , 9 5}$ & $\mathbf{1 . 2 6 0 , 0 0}$ & $\mathbf{7 . 8 6 5}$ \\
13. & Tretep & 138,00 & 175,26 & $1.270,00$ & 386 \\
\hline
\end{tabular}


Retno Rahmawati Pratiwi / Economics Development Analysis Journal 5 (2) (2016)

\begin{tabular}{llcccc}
\hline No & Kecamatan & $\begin{array}{c}\text { Luas Area } \\
(\mathrm{Ha})\end{array}$ & $\begin{array}{c}\text { Produksi } \\
(\mathrm{Ton})\end{array}$ & $\begin{array}{c}\text { Produktivitas } \\
(\mathrm{kg} / \mathrm{ha})\end{array}$ & $\begin{array}{c}\text { Jumlah } \\
\text { Petani }\end{array}$ \\
\hline 14. & Kledung & 1,10 & 1,09 & 991,50 & 6 \\
15. & Bansari & 0,80 & 0,79 & 987,20 & 12 \\
16. & Tlogomulyo & 4,80 & 4,92 & $1.025,00$ & 32 \\
17. & Selopampang & 20,90 & 22,66 & $1.084,40$ & 276 \\
18. & Gemawang & $1.524,70$ & $1.928,75$ & $1.265,00$ & 5.136 \\
19. & Bejen & $1.086,67$ & $1.385,50$ & $1.275,00$ & 1.51 \\
20. & Wonoboyo & 386,80 & 485,43 & $1.255,00$ & 1.462 \\
Jumlah & $\mathbf{8 . 1 5 8 , 5 5}$ & $\mathbf{1 0 . 2 5 4 , 3 2}$ & $\mathbf{1 . 2 5 6 , 8 8}$ & $\mathbf{3 3 . 6 5 1}$ \\
\hline
\end{tabular}

Sumber : BPS, Temanggung Dalam Angka 2015

Pada Tabel 2 diatas dapat dilihat bahwa Kecamatan Candiroto memiliki luas lahan, jumlah produksi, dan jumlah petani paling banyak dibanding Kecamatan yang lain. Tingkat produktivitas kopi Kecamatan Candiroto masih tergolong rendah bila dibandingkan dengan sentra kopi lain yang memiliki luas lahan lebih rendah dari Kecamatan Candiroto, seperti Kecamatan Gemawang dan Bejen. Berdasarkan pra survei dan wawancara dengan Staff Bidang Ekonomi BAPPEDA Kabupaten Temanggung Wisnu G.U., mengatakan bahwa petani kopi di Kabupaten Temanggung sebagian besar adalah lulusan Sekolah Dasar, sehingga pengetahuan dalam budidaya kopi berasal dari turun-temurun dan belum memperhitungkan penggunaan input yang sesuai. Bahkan informasi harga pasar kopi yang didapat oleh petani hanya berasal dari pedagang.

Berdasarkan uraian latar belakang diatas, pentingnya peran usahatani untuk meningkatkan produksi kopi agar lebih berkualitas. Penetapan Kabupaten Temanggung sebagai sentra kopi di Provinsi Jawa Tengah tidak terlepas dari berbagai masalah yang menjadi penghambat pengembangan usahatani kopi. Oleh karena itu, perlu disusun sebuah strategi pengembangan usahatani kopi di Kecamatan Candiroto Kabupaten Temanggung yang sesuai dengan kondisi dan kebutuhan di lapangan. Tujuan dari penelitian ini adalah untuk mengetahui dan mengkaji hambatan pengembangan usahatani kopi di Kecamatan Candiroto Kabupaten Temanggung dan menganalisis strategi yang tepat dalam pengembangan usahatani kopi dalam upaya peningkatan produksi di Kecamatan Candiroto Kabupaten Temanggung.

\section{METODE PENELITIAN}

Data yang digunakan dalam penelitian ini adalah data primer bersumber dari narasumber dan keyperson yang diperoleh dengan metode wawancara, observasi, kuesioner dan dokumentasi dari instansi atau pelaku terkait dalam pengembangan usahatani kopi di Kecamatan Candiroto dan data sekunder yang bersumber dari instansi terkait yaitu Dinas Perkebunan Provinsi Jawa Tengah, Dinas Pertanian, Perkebunan dan Kehutanan Kabupaten Temanggung, Dinas Perdagangan, Perindustrian dan UMKM Kabupaten Temanggung, BAPPEDA Kabupaten Temanggung, Badan Pusat Statistik dan Kantor Kecamatan Candiroto.

Dalam penyusunan penelitian ini peneliti menggunakan analisis deskriptif kualitatif, analisis deskriptif kualitatif diartikan sebagai proses pemecahan masalah yang diselidiki dengan melukiskan keadaan subyek dan obyek penelitian pada saat sekarang berdasarkan faktafakta yang tampak atau bagaimana adanya. Metode kualitatif dalam penelitian ini digunakan untuk menganalisis hambatan dalam pengembangan usahatani kopi dalam upaya 
peningkatan produksi di Kecamatan Candiroto Kabupaten Temanggung. Analisis yang dilakukan pada penelitian ini menggunakan analisis model interaktif. Analisis interaktif terdiri atas tiga alur kegiatan yang terjadi secara bersamaan, yaitu reduksi data, penyajian data, dan penarikan simpulan atau verifikasi.

\section{Analisis Hierarki Proses}

Penelitian ini menggunakan Metode Analisis Hierarki Proses (AHP) dengan tujuan untuk mengetahui program manakah yang perlu didahulukan atau diprioritaskan dalam upaya mengembangkan usahatani kopi di Kecamatan Candiroto Kabupaten Temanggung. Metode Analysis Hierarchy Process (AHP) adalah model pengambilan keputusan yang komprehensif dengan memperhitungkan hal-hal yang bersifat kualitatif dan kuantitatif. Metode AHP dapat membantu dalam menyusun suatu prioritas maupun tujuan dari berbagai pilihan dengan menggunakan beberapa kriteria (Prajanti, 2013).

Kerangka hierarki keputusan tertentu terhadap sasaran utama dapat dilihat pada Gambar 1 dibawah ini :

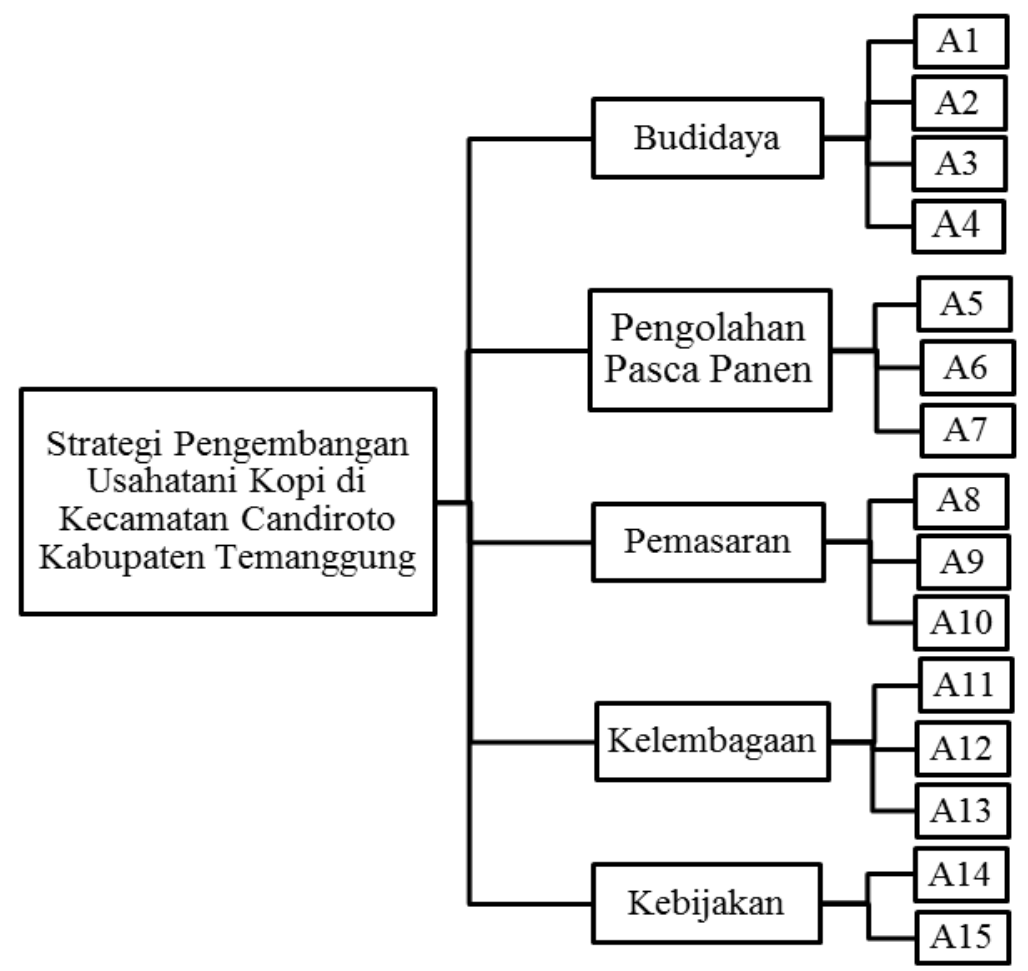

Gambar 1. Kerangka Hierarki AHP

Keterangan :

A1 : Memberikan penyuluhan untuk revitalisasi lahan kopi dan bantuan bibit yang berstandar

A2 : Memberikan pelatihan proses budidaya kopi yang mengacu pada standar ekspor

A3 : Memberikan penyediaan bantuan sarana produksi
(SAPROTAN) tepat waktu, jumlah, harga dan mutu

A4 : Merangsang peningkatan penggunaan pupuk organik dan pestisida nabati dalam budidaya kopi

A5 : Memberikan penyuluhan meningkatkan kesadaran petani melakukan penanganan pasca panen yang tepat 
A6 : Memberikan bantuan pengadaan alat pulper (mesin pengupas buah kopi basah) dan huller (mesin pengupas buah kopi kering) untuk kelompok serta dilakukan pendampingan dalam penggunaannya

A7 : Memberikan pelatihan inovasi dan diversifikasi produk untuk meningkatkan nilai tambah produksi

A8 : Memberikan sosialisasi mengenai branding dan bimbingan agar melakukan ekspor secara mandiri

A9 : Membuka peluang pasar yang menguntungkan petani

A10 : Melakukan promosi baik melalui media cetak, elektronik dan media sosial

A11 : Memberikan penyuluhan untuk penguatan efektivitas koordinasi kelembagaan kopi di seluruh level

A12 : Memberikan bantuan modal/intensif untuk kelembagaan tani yang aktif

A13 : Memaksimalkan pemberdayaan kelembagaan petani sehingga dapat membentuk sebuah jaringan kemitraan

A14 : Penetapan peraturan mengenai perlindungan harga dan tata niaga kopi

A15 : Penetapan peraturan mengenai penguatan branding kopi Temanggung

Proses AHP selanjutnya adalah melakukan skala banding berpasangan untuk menentukan susunan prioritas alternatif. Penelitian dilakukan dengan menggunakan beberapa responden yang dianggap ahli dari beberapa multidisipliner. Hasil penelitian gabungan tersebut selanjutnya diolah dengan prosedur AHP. Kemudian dilakukan running melalui program expert choice versi 9.0 akan ditunjukan hasil urutan skala prioritas secara grafis untuk mencapai "Strategi Pengembangan Usahatani Kopi di Kecamatan Candiroto".

\section{HASIL DAN PEMBAHASAN}

\section{Persistensi Inflasi}

Berdasarkan metode kualitatif deskriptif, diketahui hambatan dalam pengembangan usahatani kopi di Kecamatan Candiroto Kabupaten Temanggung adalah dalam hal budidaya, pengolahan pasca panen dan pemasaran. Hambatan dalam budidaya adalah belum terlaksananya teknik baku budidaya kopi sehingga menghasilkan kualitas hasil panen yang buruk, hambatan dalam pengolahan hasil panen adalah hasil pengolahan pasca panen yang belum diterima oleh pasar yang menyebabkan petani untuk terus mengolah hasil panen dengan alat tradisional yang menurunkan kualitas hasil olahan, hambatan dalam pemasaran adalah tertutupnya akses informasi harga membuat petani tertipu dengan harga kopi yang terjadi dipasaran secara umum, dan belum adanya brand yang menyebabkan sulitnya melakukan promosi serta membuka peluang daerah lain untuk mengakui kopi Temanggung.

Strategi pengembangan usahatani kopi di Kecamatan Candiroto dirumuskan menggunakan metode AHP (Analysis Hierarchy Process). Tujuan alternatif dan kriteria yang digunakan dalam AHP dirumuskan dari hasil survei dan diskusi dengan keyperson yang berkompeten terhadap pengembangan usahatani kopi di Kecamatan Candiroto. Sebagai prioritas pengembangan usahatani kopi, dilakukan dengan cara memilih kriteria-kriteria yang telah ditentukan yaitu aspek budidaya, aspek pengolahan pasca panen, aspek pemasaran, aspek kelembagaan, dan aspek kebijakan. Dari masing-masing aspek yang menjadi kriteria terdapat alternatif sebagai langkah pengembangan komoditas yang dipilih dari yang paling prioritas. Berdasarkan olah data dengan metode AHP diperoleh pemeringkatan bobot dari kriteria pengembangan usahatani kopi Kecamatan Candiroto sebagai berikut : 
Tabel 3. Kriteria Pengembangan Usahatani Kopi

\begin{tabular}{lll}
\hline No & Kriteria & Nilai Bobot \\
\hline 1 & Aspek Budidaya & 0.342 \\
2 & Aspek Pemasaran & 0.269 \\
3 & Aspek Pengolahan Pasca Panen & 0.223 \\
4 & Aspek Kelembagaan & 0.087 \\
5 & Aspek Kebijakan & 0.080 \\
Inconsistency Ratio $=0.09$ & \\
\hline \multicolumn{2}{l}{ Sumber : Data primer diolah, 2015 }
\end{tabular}

Berdasarkan Tabel 3 menunjukkan bahwa kriteria budidaya dengan nilai bobot 0,342 merupakan kriteria paling penting yang perlu diperhatikan dalam strategi pengembangan usahatni kopi di Kecamatan Candiroto Kabupaten Temanggung. Berikutnya secara berurutan adalah kriteria pemasaran, kriteria pengolahan pasca panen, kriteria kelembagaan, dan kriteria kebijakan. Selanjutnya program alternatif dari setiap aspek akan dijelaskan dari yang paling prioritas hingga yang paling tidak prioritas.

Selanjutnya pemeringkatan dari program alternatif dalam aspek budidaya yang terlihat dalam tabel berikut :

Tabel 4. Kriteria Budidaya

\begin{tabular}{lll}
\hline No & Alternatif Kriteria Budidaya & Nilai Bobot \\
\hline 1 & Penyuluhan revitalisasi lahan kopi dan bantuan bibit unggul & 0.280 \\
2 & Pelatihan teknik budidaya kopi yang tepat & 0.394 \\
3 & Bantuan Sarana Produksi Pertanian tepat waktu, jumlah, harga dan mutu & 0.194 \\
4 & Peningkatan penggunaan pupuk organik dan pestisida nabati & 0.132 \\
Inconsistency Ratio $=0.05$ & \\
\hline
\end{tabular}

Sumber : Data primer diolah, 2015

Dari tabel 4 tersebut dapat diketahui bahwa pelatihan teknik budidaya kopi yang tepat menjadi alternatif yang paling diprioritaskan, selanjutnya yang menjadi prioritas kedua adalah penyuluhan revitalisasi lahan kopi dan bantuan bibit unggul, kemudian yang menjadi prioritas ketiga adalah bantuan sarana produksi pertanian (SAPROTAN) tepat waktu, jumlah, harga dan mutu, sedangkan yang menjadi alternatif terakhir adalah peningkatan penggunaan pupuk organik dan pestisida nabati. Tujuan diadakannya pelatihan teknik budidaya kopi adalah agar menghasilkan peningkatan produksi dan mutu kopi yang lebih berkualitas. Sehingga dalam strategi ini dapat dilakukannya suatu kegiatan berupa Sekolah Lapang Budidaya Kopi yang lebih intensif dengan diadakannya pengawasan dan pengamatan serta melakukan penelitian lapang, guna meningkatkan dan memperbarui pengetahuan tentang budidaya kopi.

Selanjutnya pemeringkatan dari program alternatif dalam aspek pemasaran yang terlihat dalam tabel berikut :

Tabel 5. Kriteria Pemasaran

\begin{tabular}{llll}
\hline No & $\begin{array}{l}\text { Alternatif } \\
\text { Pemasaran }\end{array}$ & $\begin{array}{l}\text { Kriteria } \\
\text { Bobot }\end{array}$ \\
\hline 1 & $\begin{array}{l}\text { Sosialisasi branding dan } \\
\text { bimbingan ekspor mandiri }\end{array}$ & 0.152 \\
2 & $\begin{array}{l}\text { Membuka peluang pasar } \\
\text { yang menguntungkan petani }\end{array}$ & 0.676 \\
3 & $\begin{array}{l}\text { Melakukan promosi secara } \\
\text { luas }\end{array}$ & 0.172 \\
Inconsistency Ratio = 0.01 & \\
\hline
\end{tabular}

Sumber : Data primer diolah, 2015 
Berdasasrkan Tabel 5 dalam aspek pemasaran yang menjadi alternatif paling prioritas dalam pengembangan usahatani kopi adalah membuka peluang pasar yang menguntungkan petani, alternatif prioritas kedua adalah melakukan promosi secara luas, kemudian alternatif prioritas ketiga adalah sosialisasi branding dan bimbingan ekspor secara mandiri. Keadaaan selama ini adalah kurangnya perlindungan yang dilakukan oleh pemerintah dalam mengawasi jalannya proses pemasaran kopi. Dengan mengadakan penyuluhan mengenai bagaimana cara mendapatkan sebuah peluang dalam pasar yang tidak merugikan, sehingga mendapatkan informasi yang terbuka dalam hal harga, besarnya permintaan kopi, dan kualitas yang dibutuhkan oleh pasar. Dalam hal ini, diperlukan keaktifan petani untuk mendapatkan informasi yang detail dan real.

Selanjutnya pemeringkatan dari program alternatif dalam aspek pengolahan pasca panen yang terlihat dalam tabel berikut:

Tabel 6. Kriteria Pengolahan Pasca Panen

\begin{tabular}{llll}
\hline No & $\begin{array}{l}\text { Alternatif } \\
\text { Pengolahan Pasca Panen }\end{array}$ & $\begin{array}{l}\text { Kriteria } \\
\text { Bobot }\end{array}$ \\
\hline 1 & $\begin{array}{l}\text { Peningkatan } \\
\text { penanganan pasca panen } \\
\text { yang tepat }\end{array}$ & 0.424 \\
& $\begin{array}{l}\text { Bantuan alat pulper dan } \\
\text { huller serta pendampingan } \\
\text { pengolahan }\end{array}$ & \\
& $\begin{array}{l}\text { Pelatihan inovasi dan } \\
\text { diversifikasi olahan kopi }\end{array}$ & 0.407 \\
Inconsistency Ratio = 0.0 &
\end{tabular}

Sumber : Data primer diolah, 2015

Tabel 6 tersebut menunjukkan bahwa peningkatan kesadaran penanganan pasca panen yang tepat menjadi alternatif prioritas utama, selanjutnya pemberian bantuan alat pulper dan huller serta pendampingan pengolahan menjadi prioritas kedua dan sebagai prioritas pelatihan inovasi dan diversifikasi olahan kopi. Hal yang umum dilakukan oleh petani di Kecamatan Candiroto Kabupaten Temanggung dalam penanganan pasca panen adalah olahan kopi giling kering. Jenis olahan kopi ada dua yaitu olah kering dan olah basah. Dari kedua jenis olahan pasca panen tersebut yang paling bagus adalah olah basah karena kadar air dan kualitas biji mengalami kerusakan dapat dikontrol dengan baik. Pengolahan tersebut juga berdampak pada rasa dan aroma kopi bubuk. Karena pentingnya pengolahan pasca panen, sehingga perlunya diadakan pembinaan untuk peningkatan kesadaran petani untuk penanganan pasca panen yang benar.

Selanjutnya pemeringkatan dari program alternatif dalam aspek kelembagaan yang terlihat dalam tabel berikut :

Tabel 7. Kriteria Kelembagaan

\begin{tabular}{llrl}
\hline No & $\begin{array}{l}\text { Alternatif } \\
\text { Kelembagaan }\end{array}$ & Kriteria & $\begin{array}{l}\text { Nilai } \\
\text { Bobot }\end{array}$ \\
\hline 1 & $\begin{array}{l}\text { Penyuluhan } \\
\text { efektivitas } \\
\text { kelembagaan petani }\end{array}$ & $\begin{array}{l}\text { penguatan } \\
\text { koordinasi }\end{array}$ & 0.331 \\
2 & $\begin{array}{l}\text { Bantuan modal/insentif } \\
\text { untuk kelembagaan }\end{array}$ & 0.289 \\
& $\begin{array}{l}\text { Pemberdayaan } \\
\text { kelembagaan petani untuk } \\
\text { membentuk kemitraan }\end{array}$ & 0.379 \\
Inconsistency Ratio = 0.07 &
\end{tabular}
Sumber : Data primer diolah, 2015

Berdasarkan Tabel 7 dari aspek kelembagaan yang menjadi prioritas alternatif adalah pemberdayaan kelembagaan petani untuk membentuk kemitraan, prioritas alternatif kedua adalah penyuluhan penguatan efektivitas koordinasi kelembagaan petani, dan selanjutnya bantuan modal/insentif untuk kelembagaan. Kelompok tani merupakan kelembagaan petani yang paling dekat dengan petani. Kelompok tani yang dapat menjalankan kegiatannya secara mandiri menjadi kriteria kelompok tani yang maju atau berorientasi pada startegi bisnis. Bantuan dari pihak pemerintah maupun swasta dalam mendukung dan memfasilitasi kegiatan kemitraan petani untuk menambah mitra kerjasama dalam jaringan usaha. Melalui bentuk 
kemitraan diharapkan dapat terjadi transfer teknologi, pengetahuan dan perluasan informasi guna pengembangan usaha.
Selanjutnya pemeringkatan dari program alternatif dalam aspek kebijakan yang terlihat dalam tabel berikut :

Tabel 8. Kriteria Kebijakan

\begin{tabular}{lll}
\hline No & Alternatif Kriteria Kebijakan & Nilai Bobot \\
\hline 1 & $\begin{array}{l}\text { Penetapan peraturan perlindungan harga dan tata } \\
\text { niaga kopi }\end{array}$ & 0.6 \\
2 & $\begin{array}{l}\text { Penetapan penguatan branding kopi Temanggung } \\
\text { Inconsistency Ratio }=0.0\end{array}$ & 0.4 \\
\hline
\end{tabular}

Sumber : Data primer diolah, 2015

Berdasarkan Tabel 8 penetapan peraturan perlindungan harga dan tata niaga kopi menjadi prioritas alternatif utama dalam aspek kebijakan dan sebagai prioritas alternatif kedua dalam aspek kebijakan adalah penetapan penguatan branding kopi Temanggung. Rantai pemasaran yang panjang dan harga yang rendah masih menjadi permasalahan yang sering dialami petani. Apabila kegiatan yang dilakukan oleh pemerintah dapat menguntungkan petani dalam hal pemasaran hasil panen dan mendapat perlindungan hukum, setidaknya petani memiliki rasa aman dalam menjual hasil panennya. Dengan adanya penetapan peraturan perlindungan harga dan tata niaga kopi diharapkan dapat memberikan rasa aman, menguntungkan, dan menjaga perdagangan kopi yang transparan.

\section{SIMPULAN}

Berdasarkan hasil analisis data, dapat disimpulkan bahwa hambatan dalam pengembangan usahatani kopi adalah belum terlaksananya teknik baku budidaya kopi, hasil pengolahan pasca panen yang belum diterima oleh pasar, tertutupnya akses informasi harga, dan belum adanya brand yang menyulitkan dalam melakukan promosi. Hasil AHP menunjukkan bahwa kriteria budidaya menjadi kriteria paling prioritas. Hal tersebut sesuai dengan hasil dilapangan bahwa petani kopi masih memerlukan pengetahuan teknik budidaya untuk mengembangkan usahanya. sebagai solusi dalam pengembangan usahatani kopi melalui aspek budidaya adalah dengan pelatihan teknik budidaya kopi yang tepat yaitu sesuai dengan standar ekspor.

Minimnya pelaksanaan baku teknik budidaya oleh petani kopi dibutuhkan peran penyuluh yang harus selalu memberikan informasi terbaru mengenai pengembangan usahatani kopi serta informasi harga kopi yang berlaku dipasar. Memberikan pengawasan dan mengontrol kegiatan budidaya hingga pengolahan pasca panen yang dilakukan oleh petani. Kegiatan dapat dilakukan melalui pelatihan dan sosialisasi teknik budidaya yang dilaksanakan secara berkala, melakukan study banding ke daerah penghasil kopi, mengikuti pameran kopi, mendukung perumusan SOP kopi, dsb. pemerintah disarankan untuk melakukan pengawasan mulai dari proses awal kegiatan budidaya hingga tahap pemasaran, sehingga diharapkan petani dapat melaksanakan panen petik merah dan mendapatkan harga yang sesuai. Dari pihak swasta disarankan dapat memberikan dukungan berupa hubungan mitra usaha yang berkelanjutan.

\section{DAFTAR PUSTAKA}

Arikunto, Suharsimi. 2010. Prosedur Penelitian : Suatu Pendekatan Praktik. Revisi 14. Jakarta : Rineka Cipta

Ayelign, A. \& Sabally, K., 2013. Determination Of Chlorogenic Acids (Cga) In Coffee Beans Using Hplc. American Journal of Research Communication, (2), p.1. 
Badan Pusat Statistik. 2015. Jawa Tengah Dalam Angka 2015. BPS Provinsi Jawa Tengah

Badan Pusat Statistik. 2015. Temanggung Dalam Angka 2015. BPS Kabupaten Temanggung

Bunn, C., Laderach, P., Rivera, O. \& Kirschke, D., 2015. A Bitter Cup: Climate Change Profile Of Global Production Of Arabica And Robusta Coffee. Climatic Change, 129, pp.89 - 101.

Daniel, Moehar. 2004. Pengantar Ekonomi Pertanian. Jakarta : PT Bumi Aksara

Direktorat Jenderal Perkebunan. 2015. Rencana Strategis Direktorat Jenderal Perkebunan Tahun 2015-2019. Jakarta: Kementerian Pertanian

Elisha, L. (2015). Analisis Ekspor Kopi Indonesia Ke Amerika Serikat dengan Pendekatan Error Correction Model (Ecm) Tahun 19812013. Economics Development Analysis Journal, 4(4). doi:10.15294/edaj.v4i4.8532

General Statistic Office. 2015. Production and Planted Area of Main Perennial Coffee Crops, Main Perennial Crops and Years.General Statistic Office Of Vietnam

Gelaw, F., Speelmen, S. \& Huylenbroeck, , 2016. Farmer's Marketing Preferences in Local Coffee Markets: Evidence from a Choice Experiment in Ethiopia. Food Policy, 61, pp.92102.

Internasional Coffee Organization. 2015. World Coffee Consumption. http://www.ico.org/prices/poproduction.pdf

Jumna, B. (2015). Strategi Pengembangan Usahatani dalam Upaya Peningkatan Produksi Padi Organik di Kecamatan Sambirejo Kabupaten Sragen. Economics Development Analysis Journal, 4(3). doi:10.15294/edaj.v4i3.774

Kementerian Perdagangan. 2015. Negara Tujuan Ekspor Komoditas Kopi Indonesia. http://www.kemendag.go.id/id/view/comm odity $/ 10$

Pamoniara, W. (2013). Analisis Produktifitas Tanaman Kopi di Kecamatan Gemawang Kabupaten Temanggung. Economics Development Analysis Journal, 2(1). doi:10.15294/edaj.v2i1.1006

Prajanti, Sucihatiningsih Dian Wisika dan Avi Budi Setiawan. 2012. Ekonomi Pertanian: Sebuah Pendekatan Empiris. Semarang : UNNES Press

Prajanti, Sucihatiningsih Dian Wisika. 2013. Metode Analisis Efisiensi Produksi dan Pengambilan
Keputusan Pada Bidang Ekonomi Pertanian. Semarang : UNNES Press

Saaty, Thomas L. 1993. Pengambilan Keputusan Bagi Para Pemimpin. Terjemahan : Liana Setiono. Jakarta : PT. Pustaka Binaman Pressindo

Sugiyono. 2011. Metode Penelitian Kuanitatif Kualitatif Dan Riset And Development. Bandung : Alfabeta. 